\title{
Optimization of Noise Transfer Path Based on the Composite Panel Acoustic and Modal Contribution Analysis
}

\author{
Qiang Liu $\mathbb{D}^{1},{ }^{1}$ Xuanyi Zhou $\mathbb{D}^{2}{ }^{2}$ Jianxin Zhu $\mathbb{D}^{1,3}$ and Xiaoping Gong $\mathbb{D}^{1}$ \\ ${ }^{1}$ State Key Laboratory for High Performance Complex Manufacturing, Central South University, Changsha 410100, China \\ ${ }^{2}$ Key Laboratory of Special Purpose Equipment and Advanced Processing Technology, Zhejiang University of Technology, \\ Hangzhou, China \\ ${ }^{3}$ National Enterprise R\&D Center, Sunward Intelligent Equipment Co Ltd, Changsha 410100, China \\ Correspondence should be addressed to Xuanyi Zhou; zhouxuanyi@zjut.edu.cn
}

Received 5 August 2021; Revised 29 September 2021; Accepted 9 October 2021; Published 20 November 2021

Academic Editor: Hang Su

Copyright (C) 2021 Qiang Liu et al. This is an open access article distributed under the Creative Commons Attribution License, which permits unrestricted use, distribution, and reproduction in any medium, provided the original work is properly cited.

\begin{abstract}
The noise of a cab directly affects the comfort and labor efficiency of the operators. The optimization of the structure-borne transmission path can obviously reduce the cab noise. The method of panel acoustic contribution analysis (PACA) is used to reduce structure noise. However, most studies only consider the panel acoustic contribution of a single frequency, without considering the contribution of major frequencies synthesis to confirm the optimized panels. In this paper, a novel method is proposed based on composite panel acoustic and modal contribution analysis and noise transfer path optimization in a vibroacoustic model. First, the finite element model (FEM) and the acoustic model are established. Based on the acoustic transfer vector (ATV) method, a composite panel acoustic contribution analysis method is proposed to identify the panels affecting the noise of the field point. Combined with the modal acoustic contribution of the modal acoustic transfer vector (MATV) method, the noise field point is confirmed in the area which has the most significant influence. Second, the optimization algorithm NLOPT which is a nonlinear optimization is applied to design the areas. The noise transfer path optimization with vibroacoustic coupling response can quickly determine the optimal thickness of the panels and reduce low-frequency noise. The effectiveness of the proposed method is applied and verified in an excavator cab. The sound pressure level (SPL) the driver's right ear (DRE) decreased obviously. The acoustic analysis of the composite panel acoustic contribution and modal acoustic contribution can more accurately recognize an optimized area than the traditional PACA. This method can be applied in the optimization of the structureborne transmission path for construction machinery cab and vehicle body.
\end{abstract}

\section{Introduction}

Noise, vibration, and harshness (NVH) is usually used to evaluate the drivers' comfort of a vehicle $[1,2]$. With the increasing academic attention to the environment and the technical improvement of vibration and noise standards of construction machinery, the NVH performance of construction machinery has been adopted by major manufacturers in recent years. Drawing on the achievement of automotive NVH, analysis methods and the design of construction machinery $\mathrm{NVH}$ have been gradually formed with the finite element and boundary element as the core $[3,4]$.

For analysis and control of vibration and noise in a cab, continuous efforts have been made. Sheng and Tijs used the wavenumber finite and boundary element methods to obtain a numerical solution $[5,6]$. Li used the experimental method to obtain a structural modal of the body-in-white of a car, which provides an excellent way to solve similar problems $[7,8]$. Mohanty identified that the frequency of structural noise was less than $1 \mathrm{kHz}$, which belongs to the low and middle frequency range, and can be controlled by suppressing structural vibration [9]. Cheung performed finite element modeling of the vehicle cab after measuring the random excitation. The low-frequency structural noise of the cab was predicted when the contribution of the body panels was analyzed [10]. Hyunwoo and Siano calculated the acoustic response and predicted the noise by inputting excitation [11-13]. Guo and Cheng reduced the structure- 
borne noise since the automotive body panel vibration was controlled $[14,15]$. Bao analyzed and predicted the sound field inside the cab of the shovel loader using acoustic vibration coupling, and the design was optimized by confirming the panel with the largest acoustic contribution [16]. Long and Wolff analyzed acoustic response, panel contribution volume, and modal participation factor by applying ATV and MATV methods for the cab of a truck, and the panels were confirmed to be improved [17, 18]. Wu established HELS-based near-field acoustic holography (NAH) formulations that can analyze and rank the panel acoustic contributions toward the acoustic field and reconstructed the acoustic field inside the vehicle passenger compartment [19]. At present, the traditional method for PACA aims at the maximum sound pressure level peak at a field point. Then the panels which contribute the most to the maximum sound pressure level are recognized. Finally, the panels are ameliorated to reduce noise. However, in practice, there is often more than one sound pressure peak with small differences in each other. The contributions of a panel are also different at main frequencies. While the maximum peak of the sound pressure is reduced at a frequency, the other one may be increased at another frequency. Therefore, the effectiveness of noise reduction is unsatisfactory. In this study, a method of composite panel acoustic contribution analysis is proposed, which takes the multiple frequencies into consideration.

After recognition of the regions that contribute most to the interior noise, it is necessary to optimize the panels. Han compared three different conditions to affirm the optimum proposal [20]. Liang used structural topology optimization to modify the panels [21]. Most researchers used experiments or topology optimization methods to optimize panels to reduce the interior noise of a cab but rarely used optimization algorithms in construction machinery. Optimization algorithms have been studied widely to solve multiobjective optimization problems, such as the global optimization algorithm $[22,23]$, the local optimization algorithm without gradient [24-26], the local optimization algorithm based on gradient [27-29], and so on. The optimization of reducing noise in a cab is a constrained, multiobjective, and multivariable problem, which is suitable for the optimization algorithm without gradient. Chan and Kumar studied algorithms in the NLOPT library and selected appropriate algorithm to solve the multiobjective problem [30, 31]. The optimization algorithm in the NLOPT library can meet the requirements.

In summary, the current research mostly focuses on the single-frequency PACA while rarely considers the composite contribution of the multiple frequencies when recognizing the optimized panels. Furthermore, most of the transfer path optimization methods are topology optimization or multischeme experimental comparison, while the ways of combining the optimization algorithm with simulation software are rarely used in a cab. In this paper, the theory and method of composite panel acoustic and modal contribution analysis are constructed. The composite panel acoustic and modal contribution are integrated to determine the improved panels and areas. Then, the transfer path optimization coupling acoustic software, Python language, and algorithm are used to optimize the panels and areas. Finally, the effectiveness of the proposed method is verified in an excavator cab.

\section{Basis Analysis Theory}

2.1. Composite Panel Acoustic Contribution Analysis Method. Among the energy transferring from the vibration source to the cab panel, the bending wave is the main fluctuation form. The periodic average power transmitted by a simple harmonic bending wave is expressed as

$$
P=V_{\max , n}^{2} K_{s} \omega k^{3},
$$

where $V_{\max , n}$ is the maximum normal velocity of a thin panel structure, $K_{s}$ is the bending stiffness, $\omega$ is the angular frequency, and $k$ is the wave number. The vibration energy per unit wavelength of a simple harmonic bending wave can be expressed as

$$
E=\frac{1}{2} V_{\max , n}^{2} K_{s} k^{4} .
$$

The transmission of vibration energy within a thin panel can be determined by the maximum normal velocity at different locations.

The wave equation governing sound field is as follows:

$$
\nabla^{2} p=\frac{1}{v_{0}^{2}} \frac{\partial^{2} p}{\partial t^{2}}
$$

where $p$ denotes the sound pressure, $v_{0}$ denotes the speed of sound, $t$ denotes the time, and $\nabla^{2}$ denotes the Laplace operator. Refer to the panel theory, the vibration differential equation of the panel structure in the cab is as follows:

$$
K_{s} \nabla^{4} u+\rho_{s} h_{s} \frac{\partial^{2} u}{\partial t^{2}}=f_{s}-p,
$$

where $\rho_{s}$ denotes the density of the thin panel, $h_{s}$ denotes the thickness of the thin panel, and $f_{s}$ denotes the normal load acting on the surface of the structure per unit area.

The finite element representation is established by applying the structural dynamics equation of the panel with the wave equation and using the Galerkin method.

$$
\left[\begin{array}{cc}
M_{s} & 0 \\
\rho_{f} A^{T} & M_{f}
\end{array}\right]\left\{\begin{array}{l}
\ddot{u}_{s} \\
\ddot{p}_{f}
\end{array}\right\}+\left[\begin{array}{cc}
C_{s} & 0 \\
0 & C_{f}
\end{array}\right]\left\{\begin{array}{c}
\dot{u}_{s} \\
\dot{p}_{f}
\end{array}\right\}+\left[\begin{array}{cc}
K_{s} & -A \\
0 & K_{f}
\end{array}\right]\left\{\begin{array}{c}
u_{s} \\
p_{f}
\end{array}\right\}=\left\{\begin{array}{c}
F_{s} \\
F_{f}
\end{array}\right\}
$$


where $u_{s}$ denotes the displacement column vector of the node; $p_{f}$ denotes the sound pressure column vector of the node; $M_{s}, C_{s}$, and $K_{s}$ are the mass matrix, damping matrix, and stiffness matrix, respectively; $F_{s}$ denotes the column vector of external load acting on the structure or the sound cavity; the subscripts $s$ and $f$ denote the structure body and the sound cavity, respectively; and $A$ denotes the coupling matrix of sound pressure and displacement. Neglecting the sound absorption materials and damping materials, the acoustic cavity damping matrix and structural damping matrix are zero. Applying Fourier transform, the above equation is transformed as follows:

$$
\left(-\omega^{2} M_{f}+i \omega C_{f}+K_{f}\right) P_{f}=-\omega^{2} \rho_{f} A^{T} U_{s}+Q_{f},
$$

where $i=\sqrt{-1}, U_{s}, P_{f}$, and $Q_{f}$ are frequency-domain parameters, while $u_{s}, p_{f}$, and $F_{f}$ are the time-domain parameters. Since the acoustic cavity has no load other than the wall panel vibration, the external load $Q_{f}=0$.

Let

$$
Z=\frac{1}{-\omega^{2} M_{f}+i \omega C_{f}+K_{f}} .
$$

Then equation (6) is transformed to

$$
P_{f}=i \omega \rho_{f} A^{T} Z \dot{U}_{s} .
$$

It can be inferred that controlling the vibration speed of the thin cab panel can affect the vibration energy and acoustic radiation.

ATV illustrates the relation between sound pressure response at a field point and surface vibration velocity.

$$
P_{\text {site }}=A_{\mathrm{ATV}}^{T}(\omega) V_{n}(\omega),
$$

where $P_{\text {site }}$ denotes the sound pressure at a field point, $A_{\mathrm{ATV}}^{T}(\omega)$ denotes the acoustic transfer vector, and $V_{n}(\omega)$ denotes the normal vibration velocity of a panel. The acoustic contribution is the algebraic sum of the acoustic contribution of every element in the panel to the field points. The mathematical formula of the element acoustic contribution is as follows:

$$
P_{i}=\sum_{j=1}^{n} P_{i, j}=\sum_{j=1}^{n} \operatorname{ATV}_{j} \cdot v_{n},
$$

where $P_{i, j}$ denotes the acoustic contribution of the $i$ th element in the $j$ th panel to the field point.

Based on the structure-acoustic coupling equation, the synthetic sound pressure at the field point within the acoustic cavity is expressed as follows:

$$
P_{N}=\sum_{j=1}^{n} P_{N, j}^{\text {panel }}
$$

where $P_{N, j}^{\text {panel }}$ is the sound pressure generated by panel $j$ at site $N$ and $n$ denotes the number of all relevant panels. To quantify the contribution of the panel vibration to the sound pressure level at the field point, the sound pressure component caused by any panel $j$ at site $N$ is projected in the direction of the complex vector of the combined sound pressure to obtain the conventional contribution of the panel to the synthetic sound pressure.

$$
\left(P_{c}\right)_{N, j}=\frac{P_{N, j}^{\text {panel }} \cdot P_{N}}{\left|P_{N}\right|} .
$$

The composite panel acoustic field contribution analysis takes all sound pressure peaks into consideration, i.e., the same importance is given to all sound pressure peaks. According to the contributions to the overall sound pressure level of the field point, it is necessary to give different weighting to the sound pressure peaks, and the correction coefficient $\beta$ is introduced and defined as follows:

$$
\beta=\frac{P_{i}}{P_{\text {site }}^{\text {RMS }}}
$$

where $P_{i}$ is the peak sound pressure of interest frequency and $P_{\text {site }}^{\mathrm{RMS}}$ is the root mean square (RMS) value, and the composite panel acoustic contribution is obtained as follows:

$$
\left(P_{c}\right)_{N, j}^{\text {sum }}=\sum_{i=1}^{l} \beta \cdot\left(P_{c}\right)_{N, j}^{\text {peak }} .
$$

2.2. Modal Contribution Analysis Method. The modal acoustic transfer vector illustrates the relationship between the sound pressure at the field point and the modal participation factor, which takes into account the structural modal on the basis of ATV. In accordance with the vibration displacement vector of the surface, the normal vibration velocity vector is projected to the normal direction of the surface.

$$
V_{n}=j \omega \cdot \Phi_{n} \cdot \operatorname{MRSP}(\omega),
$$

where $\Phi_{n}$ denotes the matrix of structural modal and $\operatorname{MRSP}(\omega)$ denotes the matrix of modal participation factors. The sound pressure at the field point can be calculated as

$$
\begin{aligned}
p & =\{\operatorname{ATV}(\omega)\}^{T} \times j \omega \times \Phi_{n} \operatorname{MrSP}(\omega) \\
& =\{\operatorname{MATV}(\omega)\}^{T} \times \operatorname{MrSP}(\omega),
\end{aligned}
$$

where $\operatorname{MATV}(\omega)$ denotes the modal acoustic transfer vector and can be calculated as

$$
\{\operatorname{MATV}(\omega)\}^{T}=j \omega \cdot\{\operatorname{ATV}(\omega)\}^{T} \cdot \Phi_{n} .
$$

The modal contribution of each frequency is calculated by extracting the modal matrix to recognize the optimized area.

\section{Composite Panel Acoustic and Modal Contribution Analysis Method}

This paper uses a composite panel acoustic and modal contribution analysis method to recognize the optimized area and then uses a noise transfer path optimization with vibroacoustic coupling response to determine the optimal area to reduce low-frequency noise. 
Figure 1 shows the process of composite panel acoustic and modal contribution analysis. First, the FEM and the acoustic model of a cab are established and coupled. The structure model and the acoustic cavity model are calculated for the modal participation factor. Based on the vibroacoustic coupling model and external excitation, the SPL at the field point is calculated. The correctness of the vibroacoustic model is verified by comparison with experimental and simulation results. Second, based on the ATV method, the composite panel acoustic contribution analysis method is proposed to identify the main panels affecting the field point. Composite panel acoustic contribution analysis gives different weighting to the sound pressure peaks. Combined with the modal acoustic contribution of the MATV method, the areas which have the largest influence noise at the field point are confirmed in panels. Finally, the noise transfer path optimization with vibroacoustic coupling response analysis can determine the panel thickness and reduce low-frequency noise. The optimization algorithm NLOPT is applied to design the areas.

\section{Application and Verification}

This paper takes an excavator cab as the application target of the new method. Excavators are the most widely applied equipment in construction. For the purpose of reducing the low-frequency noise caused by panel vibration in an excavator cab, the composite panel acoustic and modal contribution analysis and noise transfer path optimization are applied. The optimization results are verified by an experiment.

\subsection{Numerical Model}

4.1.1. The Cab Structural Model. The excavator cab is mainly made of the welded panel and shell structure. Some structural parts such as small holes, chamfered corners, and tabs that have less impact on the cab model are applied to simplify the process. The material of the body in white is Q235 with $210 \mathrm{GPa}$ elastic modulus, $7850 \mathrm{~kg} / \mathrm{m}^{3}$ density, and 0.3 Poisson's ratio. The glass is added around the FEM of the body in white to constitute an enclosed cab. The elastic modulus of the glass is $72 \mathrm{GPa}$, density is $2500 \mathrm{~kg} / \mathrm{m}^{3}$, and the Poisson's ratio is 0.22 . The cab is meshed with an average mesh cell size of $10 \mathrm{~mm}$. Figure 2(a) shows the FEM of the cab with a cell number of 324072 and a node number of 319817. According to the procedure of solving the structural model of the cab, the first four structural modes of the enclosed cab are obtained, as shown in Figure 3. Most large displacements in modal shapes are concentrated in the glasses, which demonstrates that the glasses are prone to be excited vibration.

4.1.2. The Cab Acoustic Model. The acoustic model is established on the basis of the structural model. The material of the acoustic cavity is air with $340 \mathrm{~m} / \mathrm{s}$ velocity and $1.22 \mathrm{~kg} / \mathrm{m}^{3}$ density. The frequency range caused by the panel vibration is mainly $20-200 \mathrm{~Hz}$. To improve simulation accuracy, the length of the acoustic grid should meet the requirements $L \leq c_{0} / 6 f_{\max }$, where $L$ denotes the length of the divided acoustic grid cell, $c_{0}$ denotes the sound velocity, and $f_{\max }$ denotes the maximum frequency. The maximum length of the acoustic grid is $283.33 \mathrm{~mm}$. The length of the acoustic grid is set as $40 \mathrm{~mm}$. Moreover, the acoustic model is obtained with 9453 elements, as shown in Figure 2(b). Figure 4 shows the first four acoustic modes of the excavator cab. The structural modal and acoustic modal can be imported to the vibroacoustic model for acoustic response analysis.

4.1.3. The Cab Vibroacoustic Model. The structural model of the enclosed cab is first inputted into the simulation software. Then the acoustic cavity model also is imported. The field points are set up in the acoustic cavity elements. The excitation points are created under the cab. Finally, the structure model and acoustic cavity model have achieved mutual mapping by way of establishing the coupling face. The vibroacoustic coupling model of the excavator cab is established, as shown in Figure 5.

\subsection{Numerical Analysis}

4.2.1. Baseline Measurements. Figure 6 shows the process of data acquisition in the excavator cab. The vibration acceleration in the $Z$ direction of the cab suspension and the corresponding one-third octave right ear sound pressure of a medium excavator at idle speed $(1050 \mathrm{rpm})$ are measured as input to the panel acoustic contribution analysis, as shown in Figures 7 and 8, respectively. A low-frequency band, mainly $20-200 \mathrm{~Hz}$, possesses the main energy of sound pressure. The frequencies corresponding to the sound pressure peaks are $50 \mathrm{~Hz}, 100 \mathrm{~Hz}$, and so on.

4.2.2. Acoustic Response Analysis. By acoustic response analysis, the sound pressure at the field point connects with the elements in FEM. The acceleration excitation of the suspension is imported to the vibroacoustic coupling model. The frequency range of the simulation is set as $20-200 \mathrm{~Hz}$, and the step size is $1 \mathrm{~Hz}$. After the simulation calculation, Figure 9 shows the comparison simulation results with experimental results about SPL of DRE.

In the frequency range of $20-200 \mathrm{~Hz}$, the tendency of the simulation curve and the experiment curve is roughly accordant and the frequency corresponding to the peak also coincides. It shows that the simulation results can be reflected the acoustic response and verified the accuracy of the coupling model.

4.3. Composite Panel Acoustic Contribution Analysis. The excavator cab is divided into 12 panels in the acoustic model, and the panel numbers and the corresponding panel names are shown in Table 1.

As an example, Figures 10 and 11 show the panel acoustic contribution at $50 \mathrm{~Hz}$ and $100 \mathrm{~Hz}$, respectively. The panels have a great difference in contribution at diverse 


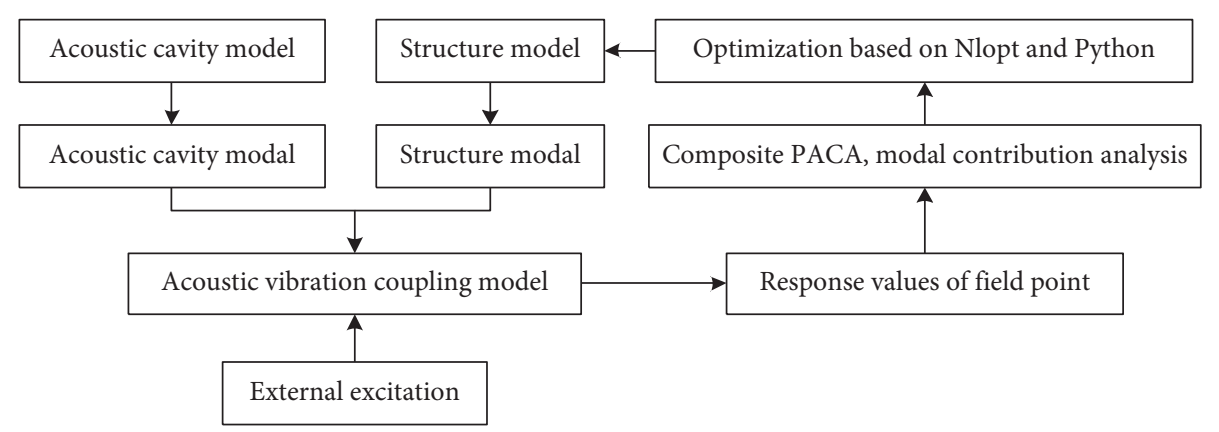

FIGURE 1: The process of composite panel acoustic and modal contribution analysis.

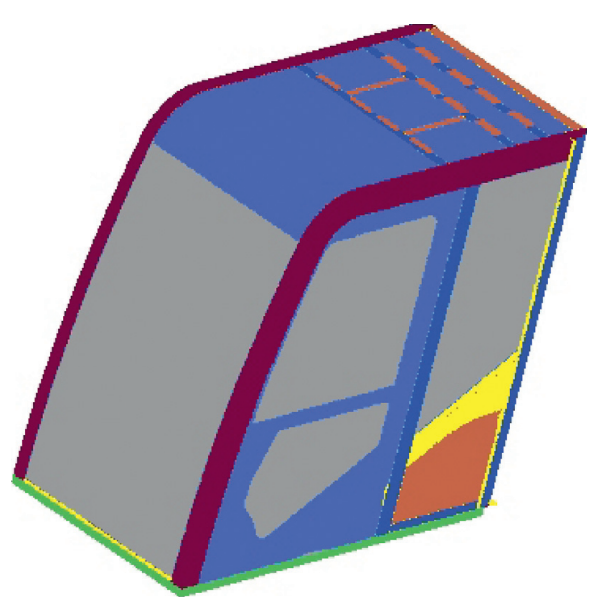

(a)

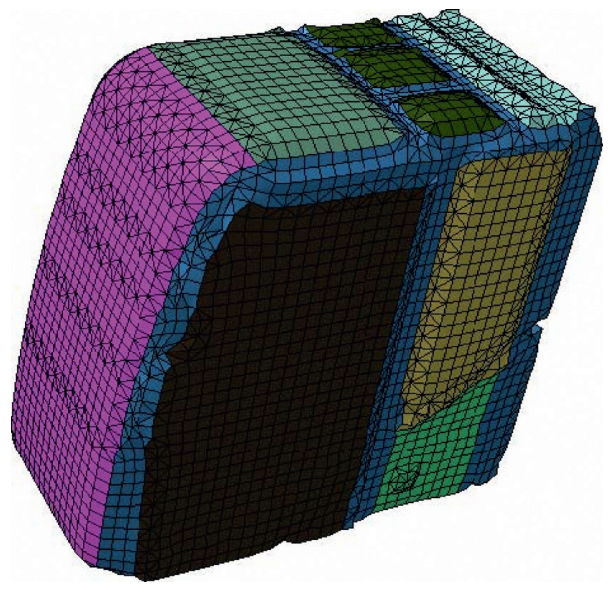

(b)

FIgure 2: The structural and acoustic model of an enclosed cab. (a) The structural model. (b) The acoustic model.

frequencies, or even opposite contributions. Hence, it is important to consider the composite contribution of the main frequencies. The composite panel acoustic contribution analysis for the partitioned panels is calculated in accordance with equations (13) and (14). The histogram is shown in Figure 12. From the figure, it can be seen that panels $1,3,4,5,6,7$, and 12 have a positive contribution to the overall SPL at the field point and the rest of the panels have a negative contribution. Among the panels contributing positively, panels with a contribution degree greater than 0.05 are the right glass, door glass, and bottom panel, which need to be optimized.

4.4. Modal Contribution Analysis. The enclosed structure modal obtained from the MSC Nastran solution is imported into the acoustic software. Moreover, the calculation results of ATV are also imported to map the structure modal to the acoustic mesh, and the modal participation factor is calculated. Then, the MATV matrix is calculated using ATV as the modal transfer matrix and combining the modal participation factors. Afterward, the MATV matrix is extracted by combining the frequency corresponding to sound pressure peaks in the DRE sound pressure response curve. According to Figure 8, the frequency of the higher peak value of sound pressure is $50 \mathrm{~Hz}$ and $100 \mathrm{~Hz}$. Figures 13 and 14 show the value of the modal contribution of the cab modal at $50 \mathrm{~Hz}$ and $100 \mathrm{~Hz}$, respectively.

The top five-mode orders in modal contributions at $50 \mathrm{~Hz}$ are $3^{\text {rd }}, 4^{\text {th }}, 6^{\text {th }}, 36^{\text {th }}$, and $40^{\text {th }}$ orders, while the top fivemode orders in modal contributions at $100 \mathrm{~Hz}$ are the $3^{\text {rd }}$, $4^{\text {th }}, 6^{\text {th }}, 23^{\text {rd }}$, and $25^{\text {th }}$ orders. The related mode vibration patterns are shown in Table 2, and the representative mode vibration patterns are shown in Figures 15, 16, and 17. From the representative modal vibration patterns, it can be concluded that the regions with greater influence on the peak sound pressure corresponding to $50 \mathrm{~Hz}$ and $100 \mathrm{~Hz}$ are mainly the center of the door glass, the center of the right glass, and the center of the bottom panel.

\subsection{Structure Optimization and Verification}

4.5.1. Structure Optimization. The method of composite panel acoustic and modal contribution analysis identified the key locations for improvement i.e. the door glass, the right side glass, and the bottom panel. The optimization method of the noise transfer path is adopted to reduce cab noise. Since the upper part of the bottom panel is the seat and the bottom is the hydraulic pipeline, it is not easy to change the structure. Thus, the thickness optimization of the center of the bottom panel is not considered. The structure of the excavator cab is optimized 


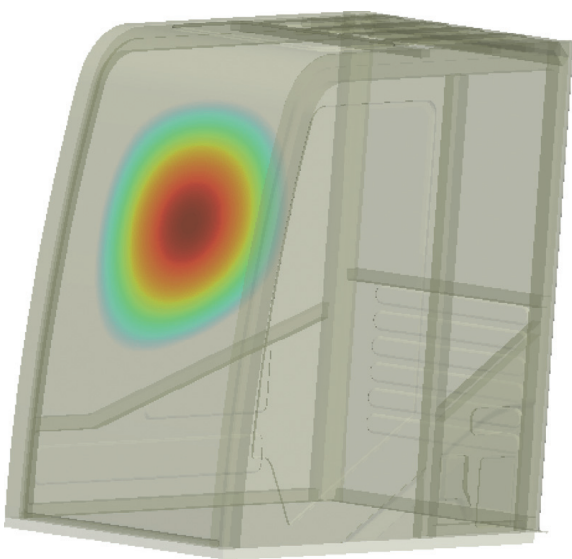

25.7 Hz: $1^{\text {st }}$ structural modal

(a)

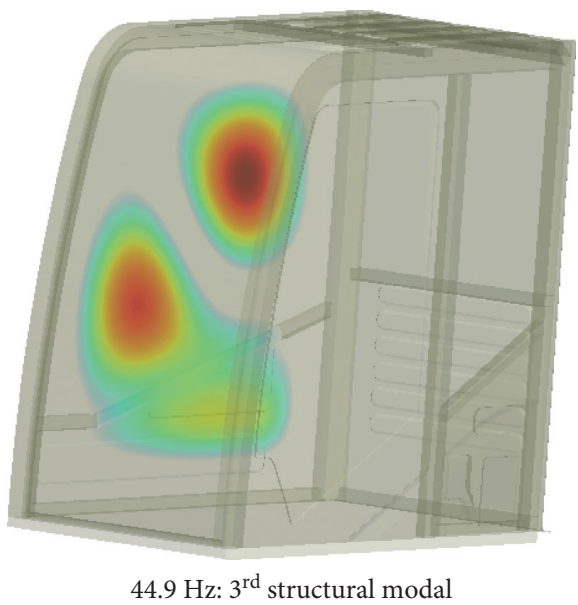

(c)

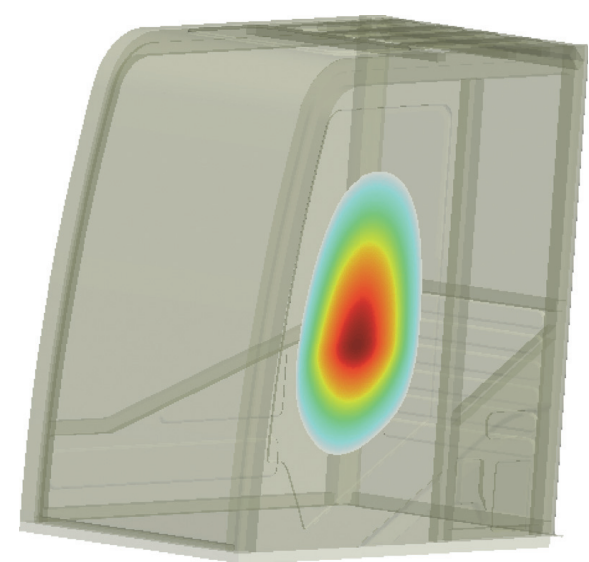

$32.8 \mathrm{~Hz}: 2^{\text {nd }}$ structural modal

(b)

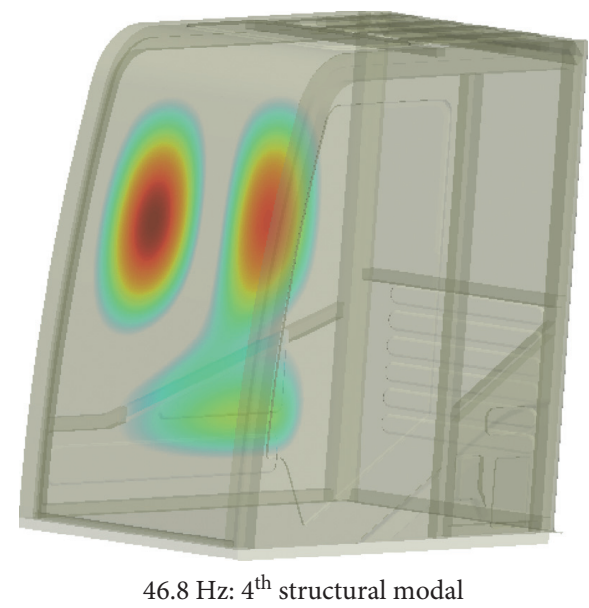

(d)

Figure 3: The structural modal of an enclosed cab. (a) $25.7 \mathrm{~Hz}: 1^{\text {st }}$ structural modal. (b) $32.8 \mathrm{~Hz}: 2^{\text {nd }}$ structural modal. (c) $44.9 \mathrm{~Hz}: 3^{\text {rd }}$ structural modal. (d) $46.8 \mathrm{~Hz}: 4^{\text {th }}$ structural modal.

using the NLOPT optimization program combining with the acoustic software. The NLOPT script is shown in Figure 18. The left side door glass center and the right glass center can be optimized. NLOPT involves various kinds of optimization algorithms with a uniform interface; the derivative-free optimization with LN_COBYLA function is suitable for the accuracy and speed of the optimization.

Applying the same boundary conditions and excitation conditions to the optimized model, the optimization program is terminated after 20 iterations. Moreover, an optimal design is found that the total weight of the whole board is less than $35 \mathrm{~kg}$, and the sound pressure level is low. After the optimization, the thickness of the glass on the right is $0.00566 \mathrm{~m}$, and the thickness of the left side door glass is $0.0062 \mathrm{~m}$. The optimized sound response in the cab is analyzed. Figure 19 shows the optimized DRE sound pressure curve and the original DRE sound pressure curve. It can be seen that the SPL at the frequency of $100 \mathrm{~Hz}$ is reduced from $53.06 \mathrm{~dB}$ to $51.36 \mathrm{~dB}$. Although the SPL in the frequency range from $120 \mathrm{~Hz}$ to $200 \mathrm{~Hz}$ increased, the total sound pressure has been reduced by $2.3 \mathrm{~dB}$, which indicates the direction of noise reduction for the cab.

4.5.2. Experimental Verification. According to the results of the structure optimization, it can be concluded that the driver's right ear noise can be reduced by increasing the thickness of the right glass and left side door glass.

The manual scheme is experimented by adding a mass block on the right glass and left side door glass, as shown in Figures 20 and 21 .

When the right ear noise is collected under the $1050 \mathrm{rpm}$ working condition, compared with baseline measurement results, as shown in Figure 22, the sound pressure level is reduced by $3.18 \mathrm{~dB}$ in the frequency band of $20 \mathrm{~Hz}-200 \mathrm{~Hz}$, and the overall sound pressure level is reduced by $2.25 \mathrm{~dB}$. The gap is because the sound pressure level of $315 \mathrm{~Hz}$ and $400 \mathrm{~Hz}$ and other medium and high-frequency noise increases, which leads to the noise level reduction of the whole frequency band. The experiment proves that the low-frequency noise can be reduced by thickening the panels. 


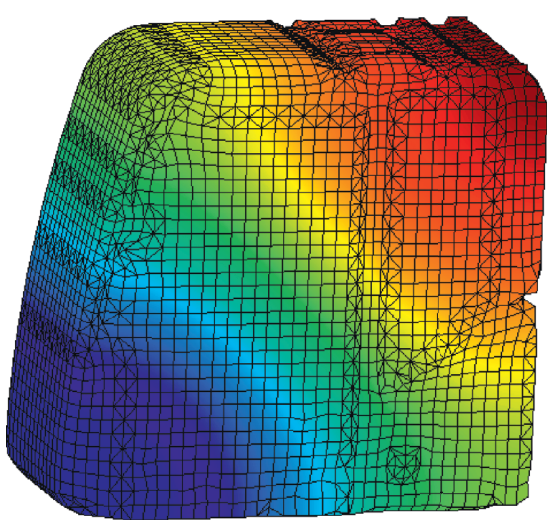

$98.6 \mathrm{~Hz}: 1^{\text {st }}$ acoustic modal

(a)

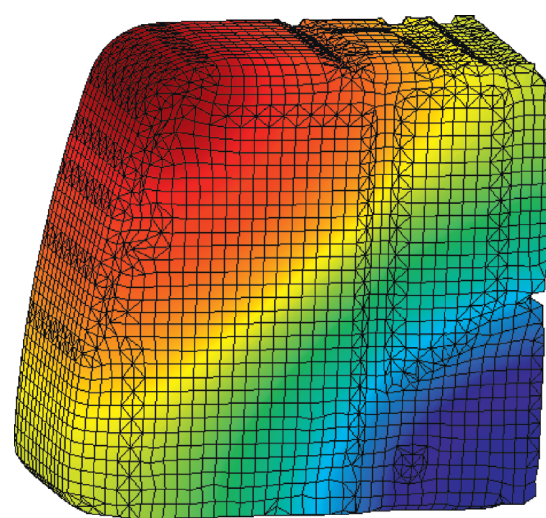

105.6 Hz: $2^{\text {nd }}$ acoustic modal

(b)

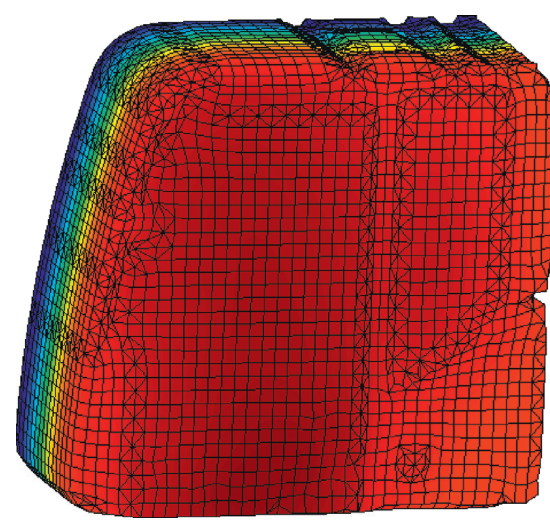

184.7 Hz: $4^{\text {th }}$ acoustic modal

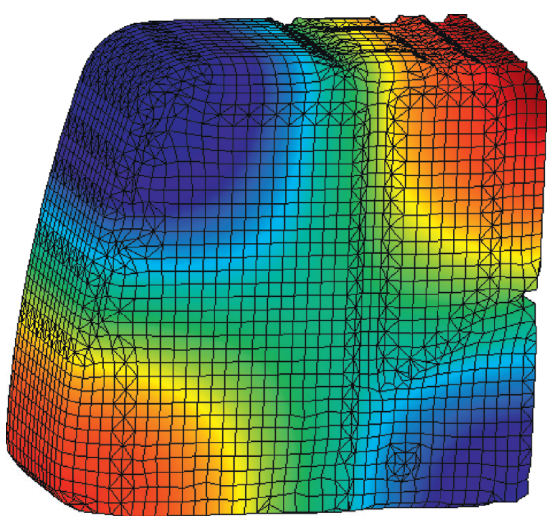

147.4 Hz: $3^{\text {rd }}$ acoustic modal

(c)

(d)

Figure 4: The acoustic modal of the cab. (a) $98.6 \mathrm{~Hz}: 1^{\text {st }}$ acoustic modal. (b) $105.6 \mathrm{~Hz}: 2^{\text {nd }}$ acoustic modal. (c) $147.4 \mathrm{~Hz}: 3^{\text {rd }}$ acoustic modal. (d) $184.7 \mathrm{~Hz}: 4^{\text {th }}$ acoustic modal.

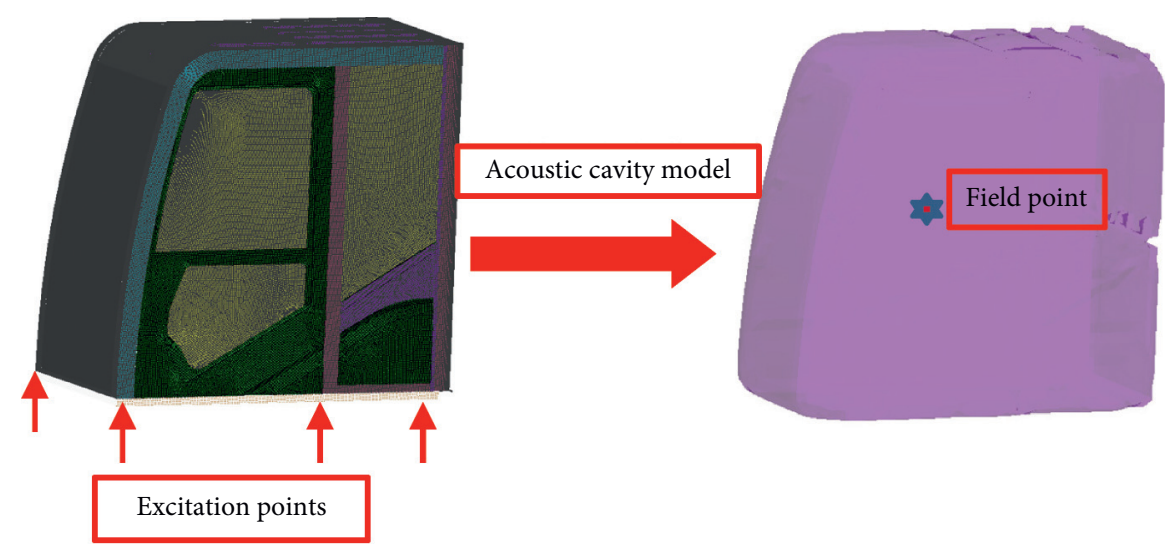

FIgURE 5: Cab vibroacoustic coupling model. 


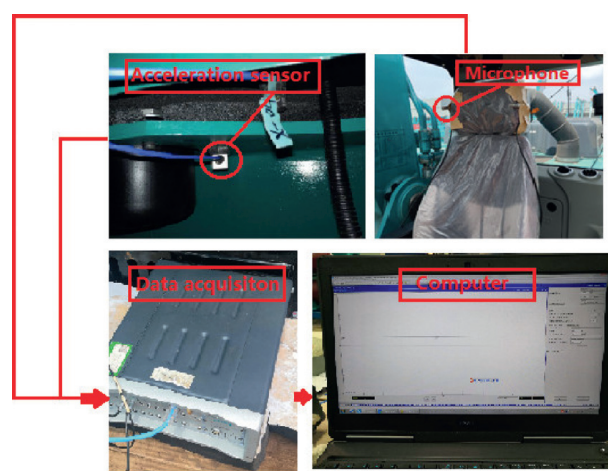

FIGURE 6: Baseline measurements for vibration and noise.

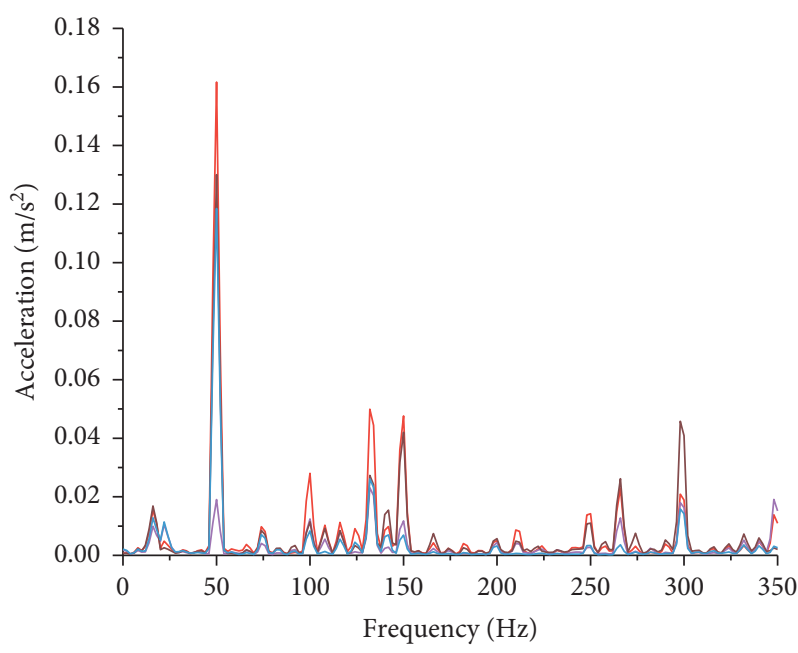

— Left front passive

— Right front passive

— Left back passive

_ Right back passive

Figure 7: Acceleration excitation at $1050 \mathrm{rpm}$.

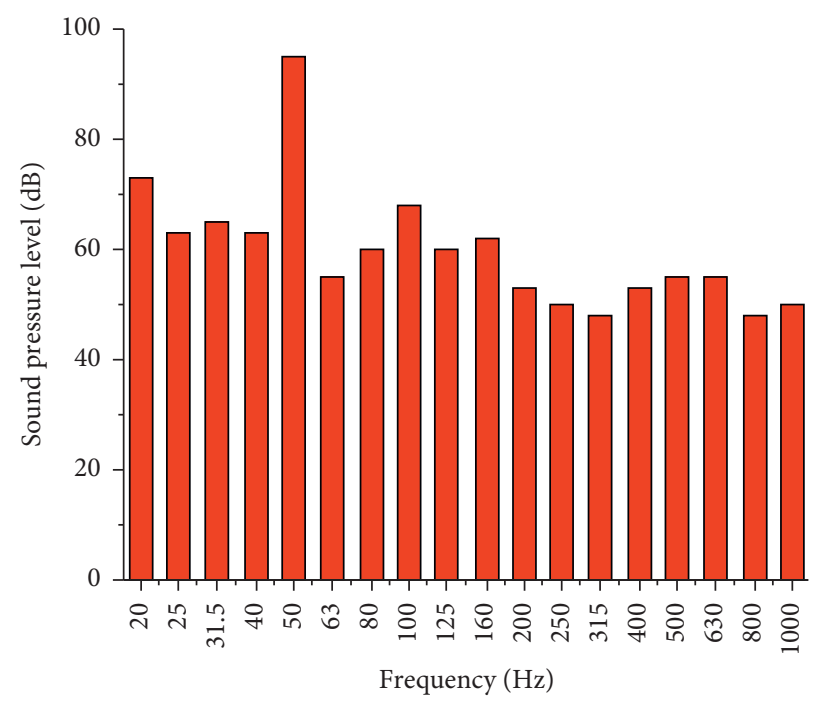

Figure 8: 1/3 octave band at the right ear of the cab. 


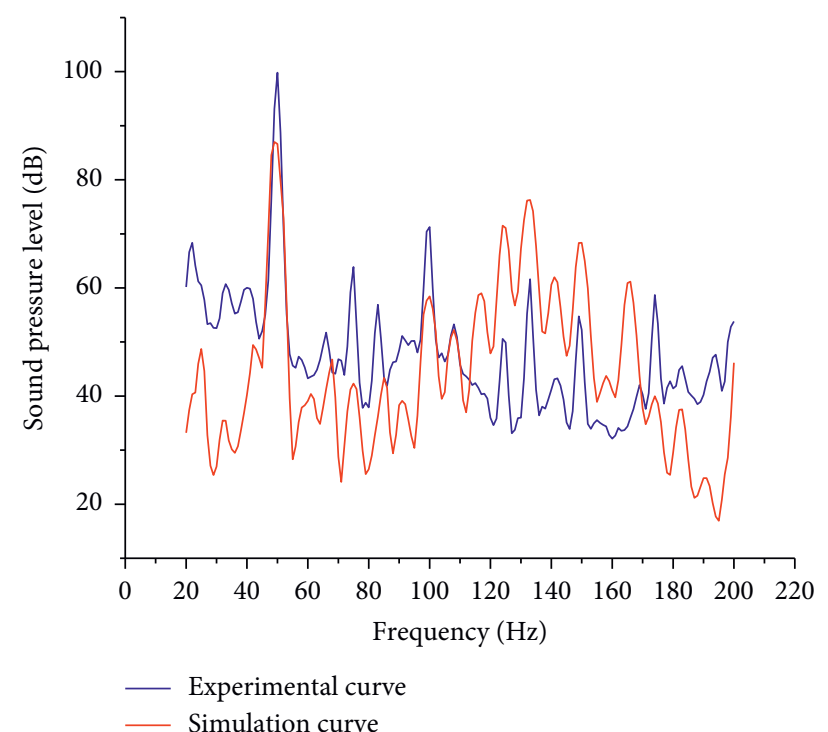

Figure 9: Simulation and experimental SPL curve.

TABLE 1: Cab panel division.

\begin{tabular}{|c|c|c|c|}
\hline Panel number & Panel name & Panel number & Panel name \\
\hline 1 & Right side glass & 7 & Left side door glass \\
\hline 2 & Right fence panel & 8 & Left rear top glass \\
\hline 3 & Front glass & 9 & Left rear bottom glass \\
\hline 4 & Roof front glass & 10 & Rear side glass \\
\hline 5 & Central roof enclosure & 11 & Rear side panel \\
\hline 6 & Roof rear enclosure & 12 & Base panel \\
\hline
\end{tabular}

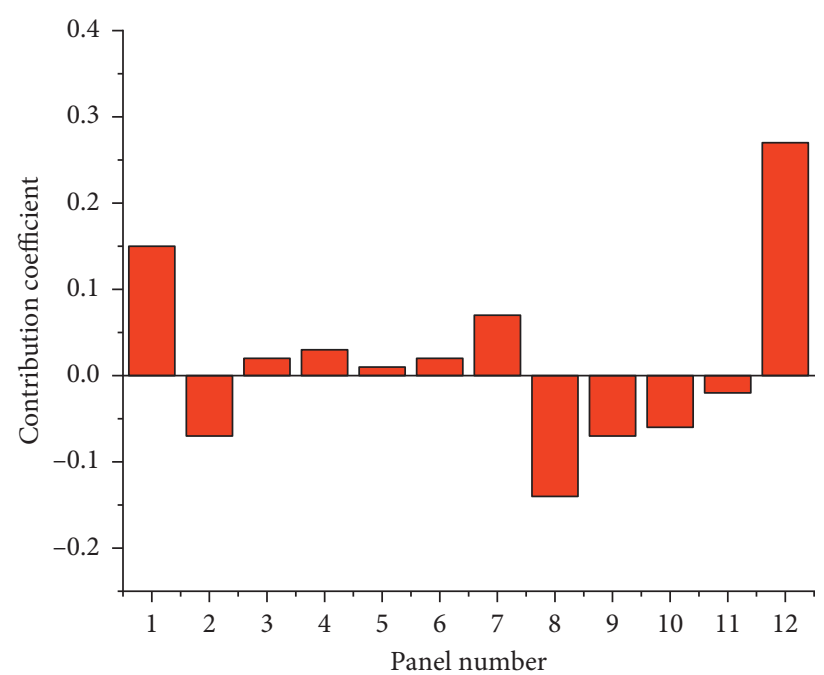

Figure 10: The panel acoustic contribution at $50 \mathrm{~Hz}$. 


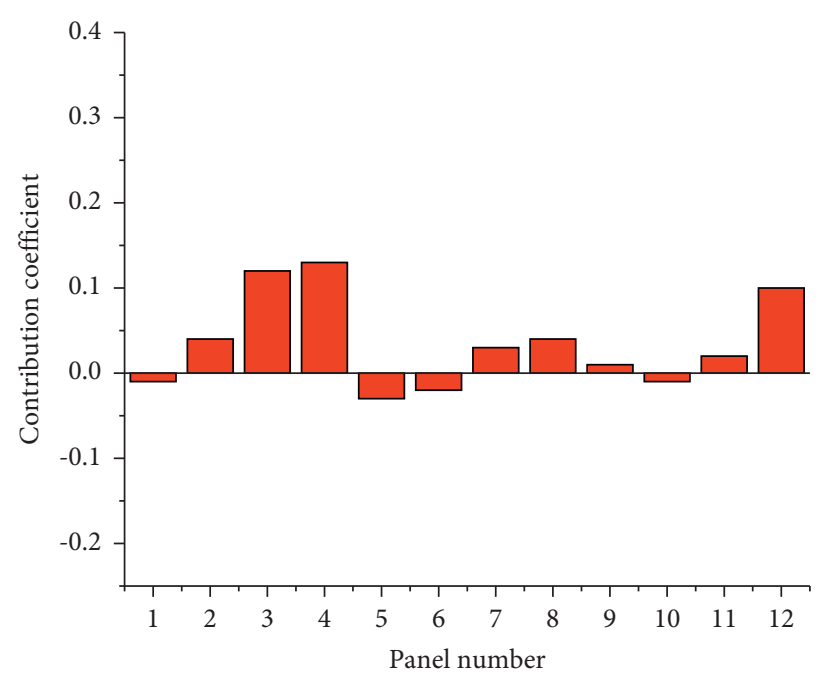

FIgUre 11: The panel acoustic contribution at $100 \mathrm{~Hz}$.

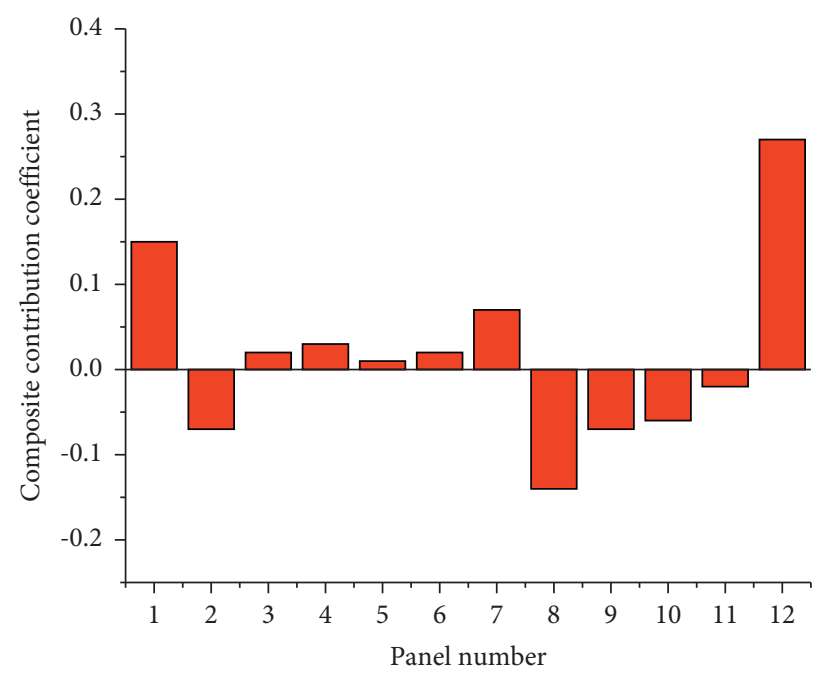

Figure 12: The composite panel acoustic contribution.

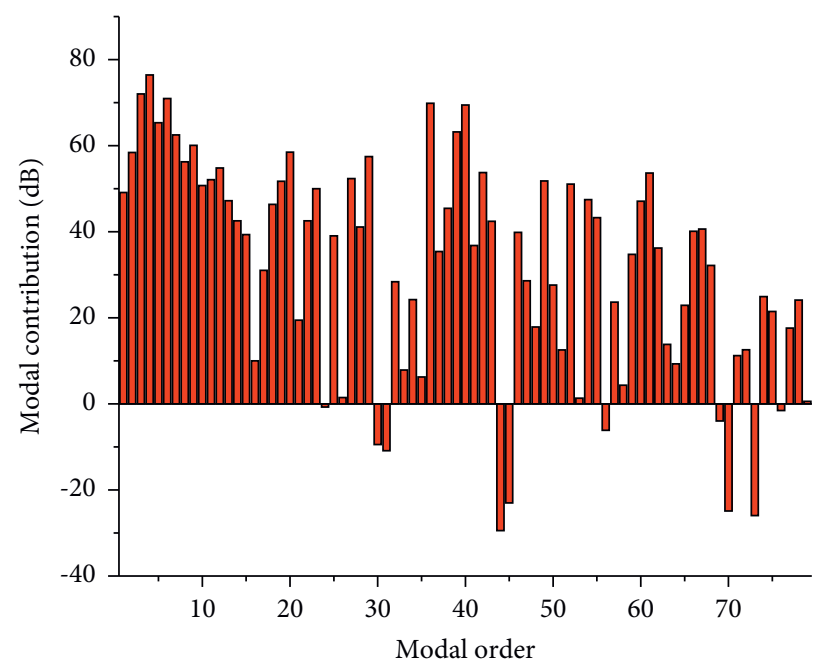

Figure 13: Modal contribution of the cab at $50 \mathrm{~Hz}$. 


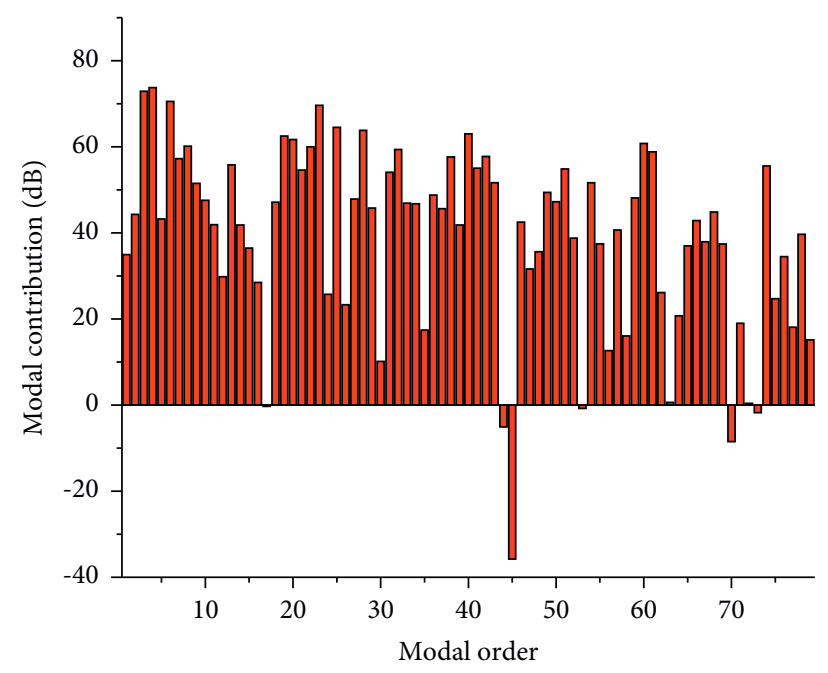

Figure 14: Modal contribution of the cab at $100 \mathrm{~Hz}$.

TABle 2: Manifestation of the relevant mode vibration pattern.

\begin{tabular}{lc}
\hline Modal order & Modal vibration expression \\
\hline 3 & Base panel \\
4 & Right side glass \\
6 & Door panel glass \\
23 & Front glass \\
25 & Door panel glass \\
36 & Front glass, roof glass \\
40 & Roof glass \\
\hline
\end{tabular}

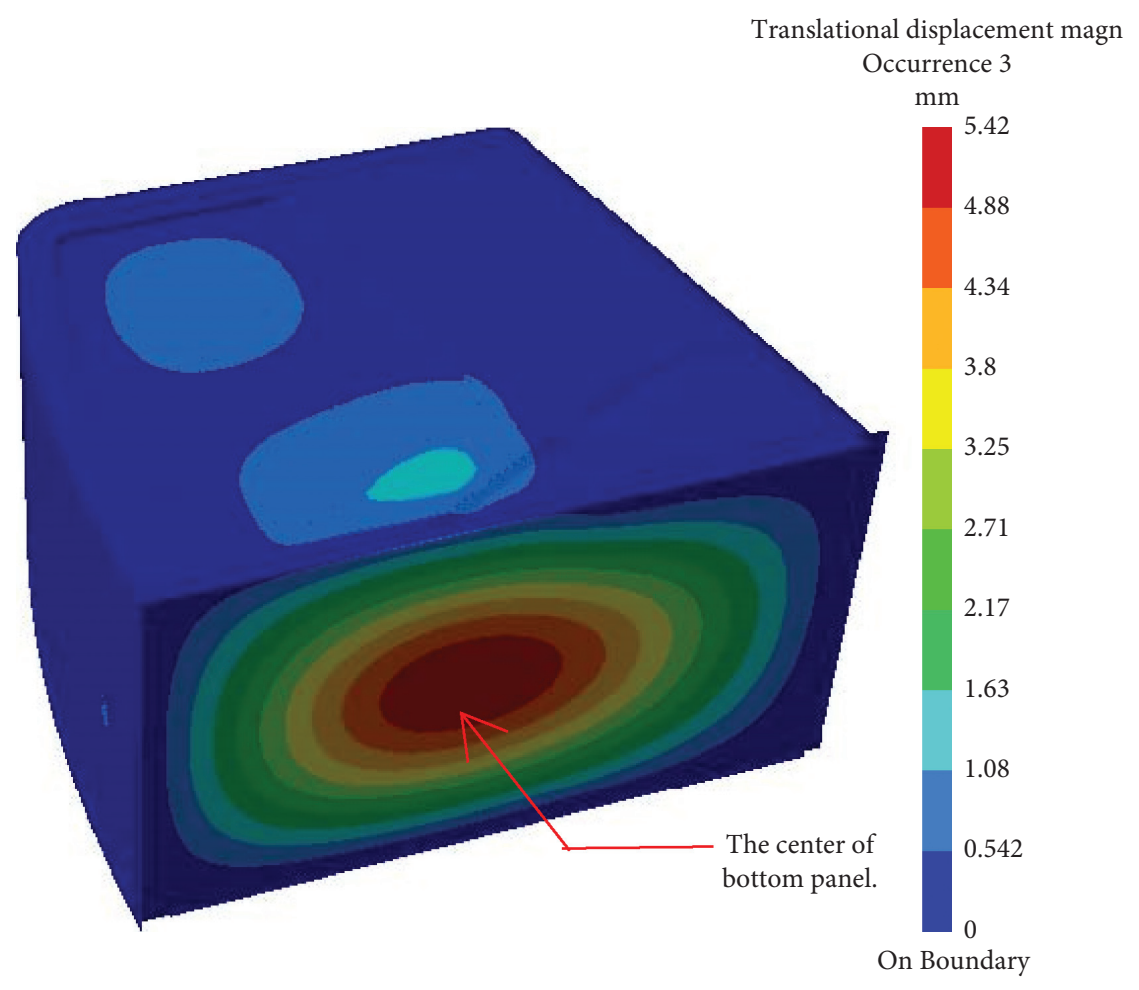

FIgURe 15: Third-order vibroacoustic coupling modal. 


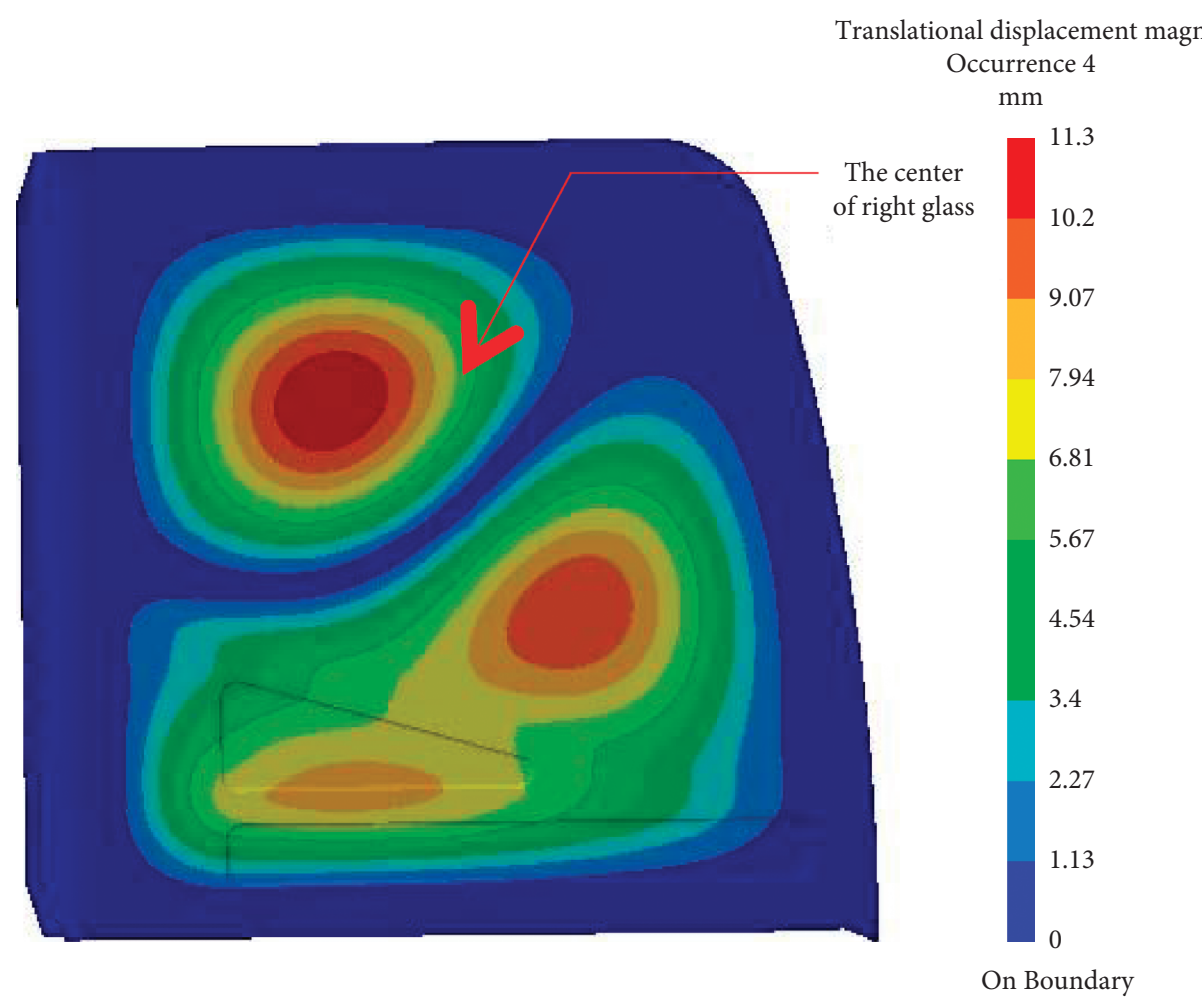

Figure 16: Fourth-order vibroacoustic coupling modal.

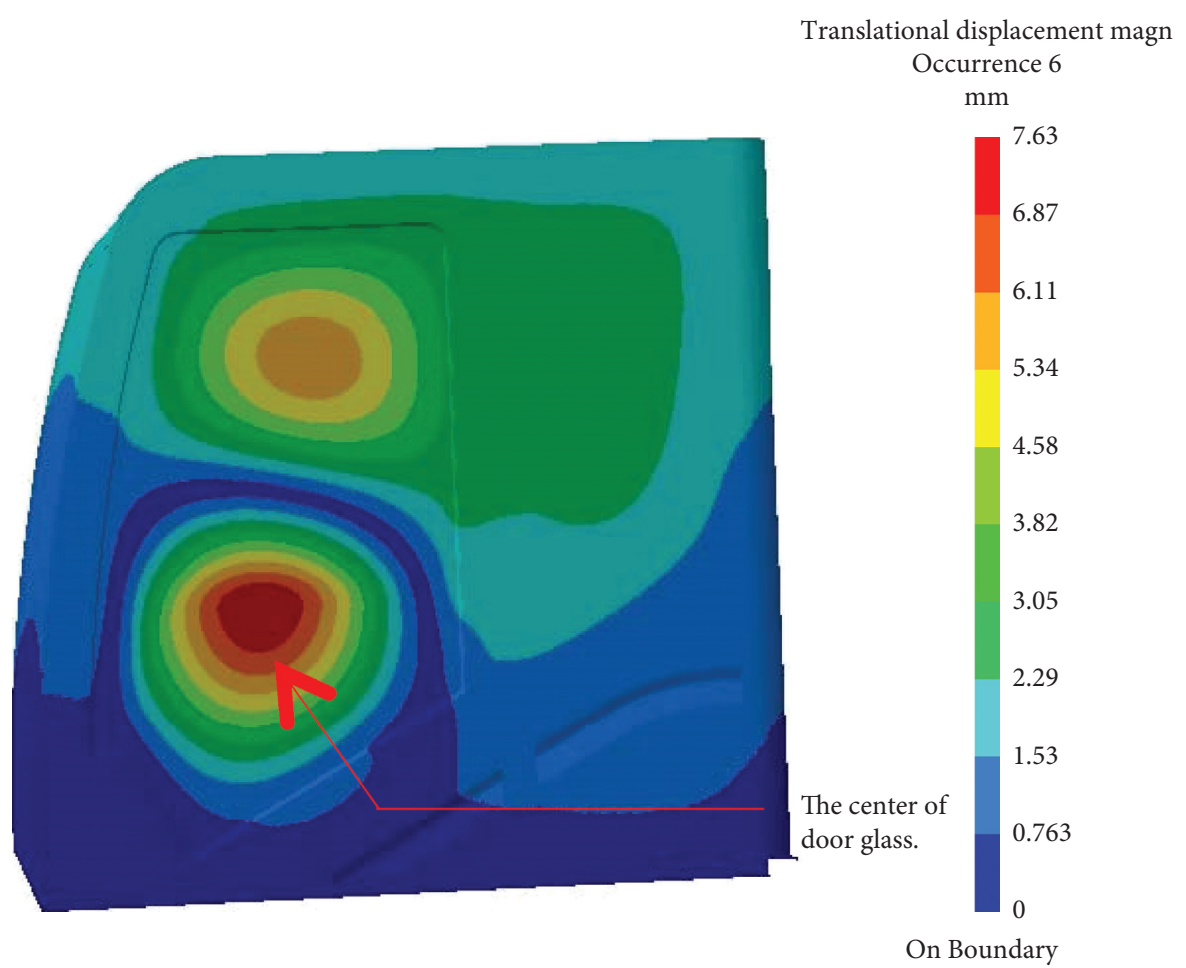

FIGURE 17: Sixth-order vibroacoustic coupling modal. 
\#USER INPUT: Actran main input file

actran_MFR_file='coupled_MFR.edat'

structure_modal_file='structure_mode.edat'

\#USER INPUT: number of iteration

$\mathrm{n} \_$iteration $=20$

\#USER_INPUT: the initial value

initial_thickness $=[5,5]$

\#USER_INPUT: lower and upper band for the

variables

lower_band $=[3,3]$

upper_band $=[7,7]$

\#USER_INPUT: mass limit

mass_limit $=35$

FIGURE 18: Part of the optimized program script.

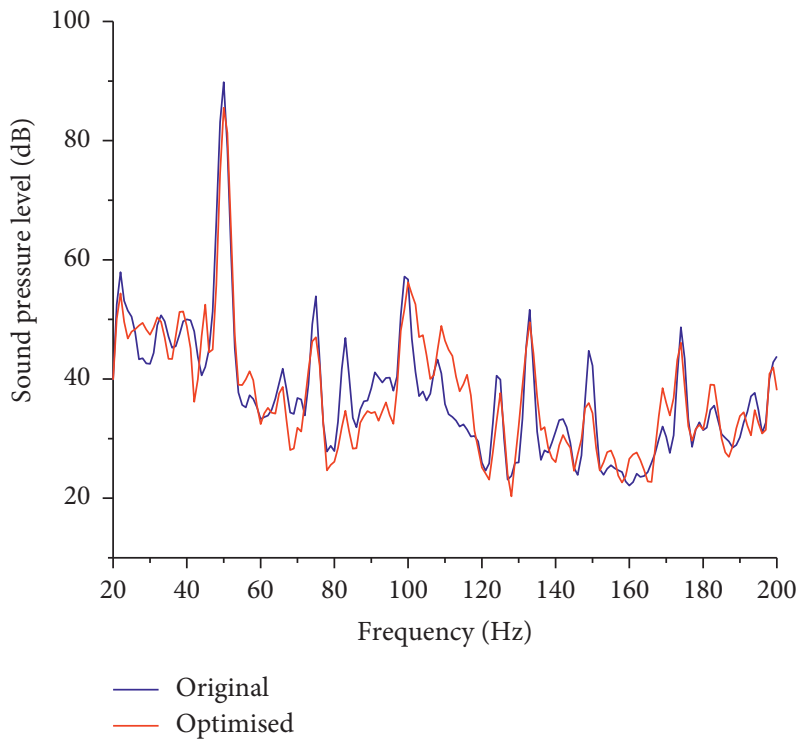

FIGURE 19: Original and optimized sound response curve.

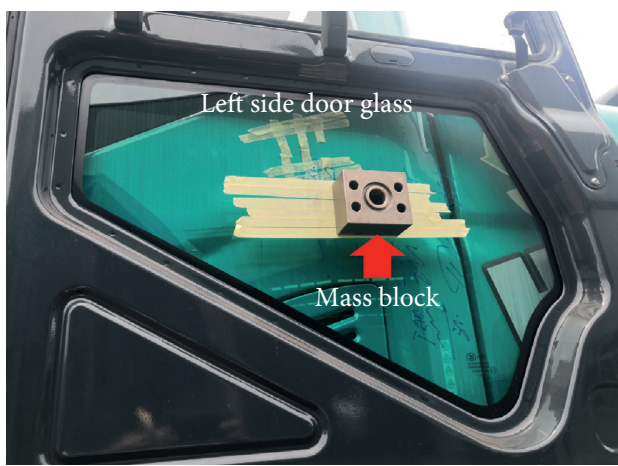

FIgURE 20: Manual verification on the left side door glass. 


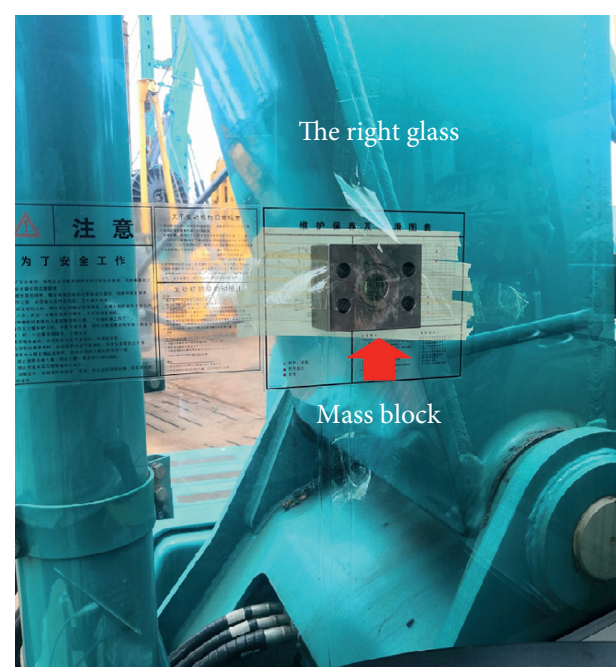

FIGURE 21: Manual verification on the right glass.

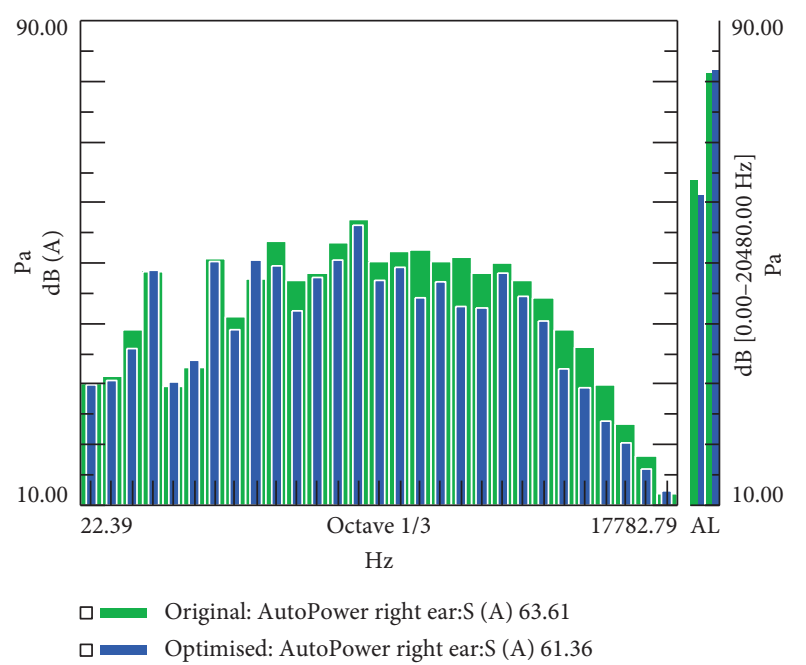

Figure 22: Comparison of right-ear noise experiment values of the cab before and after optimization.

\section{Conclusion}

Reducing the vibration noise usually achieved by improving the structure, but how to quickly and accurately identify and optimize the structure with a large contribution, is a challenge. In this paper, a method of noise transfer path optimization based on the composite panel acoustic and modal contribution analysis is proposed. The acoustic transfer vector method is used to analyze the acoustic characteristics in the vibroacoustic model. To avoid the lack of considering a single frequency contribution in the traditional panel acoustic contribution analysis, the composite panel acoustic contribution analysis that takes the multiple frequencies into consideration is proposed. Synthesizing panel contribution and modal contribution results, the panels and areas that need to be optimized identified. The parameter optimization method coupling acoustic software, Python language, and algorithm is adopted for the target panel and areas. The method is verification in an excavator cab. The acoustic response of the excavator cab is consistent with the experimental sound pressure curve at the field point. By optimizing the thickness of the right glass and left side door glass, the overall sound pressure level at DRE is reduced by $2.25 \mathrm{~dB}$. The experimental result verifies the feasibility of analysis and optimization of the noise based on the composite panel contribution and modal acoustic contribution methods, which provide a reference for passive noise control in a cab.

\section{Data Availability}

The data used to support the findings of this study have not been made available because the data are one of the research results of Sunward Intelligent Equipment Co., Ltd.

\section{Conflicts of Interest}

The authors declare that they have no conflicts of interest.

\section{Acknowledgments}

This study was supported by Top Ten Technical Research Projects in Hunan Province (Research on digital prototype and digital twin technology of the rotary drilling), the 111 Project (No. D16004), Hunan Provincial Natural Science Foundation (2020JJ5173), and the National Natural Science Foundation of China (51809091).

\section{References}

[1] B. Challen, "Automotive NVH career needs," Sound and Vibration, vol. 47, pp. 5-6, 2013.

[2] J. Gomez and J. Williams, "Analysis of acoustic characteristics of a car cabin using computer-aided engineering," Applied Mechanics and Materials, vol. 268-270, p. 883, 2013.

[3] Y. Z. Mi, Y. Q. Zhou, and L. Wang, "Vibration and noise damping treatment for an excavator cab," Advanced Materials Research, vol. 889-890, pp. 455-458, 2014.

[4] M. Hosseini Fouladi, M. J. M. Nor, and A. K. Ariffin, "Spectral analysis methods for vehicle interior vibro-acoustics identification," Mechanical Systems and Signal Processing, vol. 23, no. 2, pp. 489-500, 2009.

[5] X. Sheng, C. J. C. Jones, and D. J. Thompson, "Prediction of ground vibration from trains using the wavenumber finite and boundary element methods," Journal of Sound and Vibration, vol. 293, no. 3-5, pp. 575-586, 2006.

[6] E. Tijs, J. Wind, and D. Fernández Comesaña, "High resolution panel noise contribution method," SAE Technical Paper, vol. 01, pp. 94-104, 2011.

[7] H. Li and F. Shibo, "Experimental modal analysis of car's body-in-white," Sustainable Construction Materials and Computer Engineering, vol. 346, pp. 627-633, 2012.

[8] S. Marburg, H.-J. Beer, J. Gier, H.-J. Hardtke, R. Rennert, and F. Perret, "Experimental verification of structural-acoustic modelling and design optimization," Journal of Sound and Vibration, vol. 252, no. 4, pp. 591-615, 2002.

[9] A. R. Mohanty, B. D. St Pierre, and P. Suruli-Narayanasami, "Structure-borne noise reduction in a truck cab interior using numerical techniques," Applied Acoustics, vol. 59, no. 1, pp. 1-17, 2000. 
[10] K. Cheung, R. G. Southwick, and J. P. Campbell, "Low frequency noise prediction and control," in Proceedings of the 2012 IEEE 11th International Conference on Solid-State and Integrated Circuit Technology, pp. 531-534, Xi'an, October 2012.

[11] Y. Hyunwoo and S. Kwon Lee, "Analysis of influence of oil pan structure modification on radiation noise of an engine using fem," Transaction of the Korean Society of Automotive Engineers, vol. 25, pp. 573-580, 2017.

[12] D. Siano and S. Giacobbe, "Radiated engine noise prediction using multi-body simulation," in Proceedings of the EurodynInternational Conference on Structural Dynamics, pp. 31103117, Leuven, Belgium, 2011.

[13] S. Chen, D. Wang, J. Song, and G. Tan, "Interior noise prediction and analysis of heavy commercial vehicle," $S A E$ Technical Papers, vol. 13, pp. 263-272, 2011.

[14] R. Guo, L. J. Zhang, J. Zhao, and H. Zhou, "Interior structureborne noise reduction by controlling the automotive body panel vibration," Journal of Automobile Engineering, vol. 226, no. 7, pp. 943-956, 2012.

[15] G. Cheng, D. W. Herrin, J. Liu, and J. Stencel, "Determination of acoustic emissions using panel contribution analysis and scale modeling," Applied Acoustics, vol. 155, pp. 63-74, 2019.

[16] G. Bao and G. Shao, "Identification and contribution analysis of vehicle interior noise based on acoustic array technology," Advances in Mechanical Engineering, vol. 9, pp. 1-12, 2017.

[17] M. Long and W. Xia, "Analysis of vehicle interior low-frequency noise based on ATV," Applied Mechanics and Materials, vol. 494-495, pp. 78-81, 2014.

[18] O. Wolff and R. Sottek, "Panel contribution analysis-an alternative window method," SAE Paper, vol. 22, pp. 74-84, 2005.

[19] S. F. Wu, M. Moondra, and R. Beniwal, “Analyzing panel acoustic contributions toward the sound field inside the passenger compartment of a full-size automobile," Journal of the Acoustical Society of America, vol. 137, no. 4, pp. 2101-2112, 2015.

[20] X. Han, Y.-J. Guo, H.-D. Yu, and P. Zhu, "Interior sound field refinement of a passenger car using modified panel acoustic contribution analysis," International Journal of Automotive Technology, vol. 10, no. 1, pp. 79-85, 2009.

[21] X. H. Liang, P. Zhu, and Z. Q. Lin, "Acoustic analysis and topology optimization of auto-body using CAE Method," Machine Design \& Research, vol. 6, pp. 64-66, 2006.

[22] H. Su, C. Yang, H. Mdeihly, A. Rizzo, G. Ferrigno, and E. D. Momi, "Neural network enhanced robot tool identification and calibration for bilateral teleoperation," IEEE Access, vol. 9, pp. 70-84, 2019.

[23] Y. Hu, H. Su, L. Zhang, S. Miao, G. Chen, and A. Knoll, "Nonlinear model predictive control for mobile robot using varying-parameter convergent differential neural network," Robotics, vol. 8, no. 3, pp. 64-85, 2019.

[24] Z. Li, B. Huang, Z. Ye, M. Deng, and C. Yang, "Physical human-robot interaction of a robotic exoskeleton by admittance control," IEEE Transactions on Industrial Electronics, vol. 65, no. 12, pp. 1-11, 2018.

[25] X. Zhou, W. Qi, S. E. Ovur et al., "A novel muscle-computer interface for hand gesture recognition using depth vision," Journal of Ambient Intelligence and Humanized Computing, vol. 11, pp. 1-12, 2020.

[26] H. Su, W. Qi, Y. Hu et al., “Towards model-free tool dynamic identification and calibration using multi-layer neural network," Sensors, vol. 19, pp. 36-53, 2019.
[27] Z. Li, B. Huang, A. Ajoudani, C. Yang, C. Yi-Su, and A. Bicchi, "Asymmetric bimanual control of dual-arm exoskeletons for human-cooperative manipulations," IEEE Transactions on Robotics, vol. 7, pp. 264-271, 2017.

[28] X. Zhou, J. He, Q. He, C. Ren, Bhushan, and M. He, "Motion kinematics analysis of a horse inspired terrain-adaptive unmanned vehicle with four hydraulic swing arms," IEEE Access, vol. 8, pp. 194351-194362, 2020.

[29] Z. Li, Y. Yuan, L. Luo et al., "Hybrid brain/muscle signals powered wearable walking exoskeleton enhancing motor ability in climbing stairs activity," IEEE Transactions on Medical Robotics and Bionics, vol. 1, no. 4, pp. 218-227, 2019.

[30] U. Kumar, S. Soman, and J. Deva, "Benchmarking NLopt and state-of-the-art algorithms for continuous global optimization via [formula omitted]," Swarm \& Evolutionary Computation, vol. 27, pp. 116-131, 2015.

[31] B. P. Chan, "YAM2: yet another library for the M2 variables using sequential quadratic programming," Computer Physics Communications, vol. 264, pp. 107967-107979, 2021. 